\title{
DECISION TREES: COMPARING REPORTED INTENTIONS AND THEORETICALLY EXPECTED INTENTIONS IN URBAN CONTEXT
}

\author{
Jimmy Bordarie \\ Departement Techniques of Commercialization, EE 1901 QualiPsy, University of Tours (France)
}

\begin{abstract}
The research concerns the validation of an extended version of the theory of planned behaviour (TPB). This model argues that the prediction of intentions depends on three determinants: attitude, perceived social norms and behavioural control. Our model integrates cognitive aspects (such as beliefs, importance or perceived effect) and past behaviours (based on habits such as frequency or duration of behaviour).

The second objective is to provide a differential perspective. The construction of a decision tree will make it possible to distinguish and to compare reported intention and the expected intention that participants should have reported based on the prediction model.

In order to test our model, we are interested in a new public policy in Angers (France, Pays de la Loire). The latter concerns traffic calming with the generalised reduction of the speed limit from $50 \mathrm{~km} / \mathrm{h}$ to $30 \mathrm{~km} / \mathrm{h}$. We are studying the intention of young drivers to respect this $30 \mathrm{~km} / \mathrm{h}$ speed limit.

Participants are drivers $(\mathrm{n}=129$, Mean Age=22.4 y.o., $\mathrm{SD}=3.8$ ). They completed a questionnaire based on the extended version of the TPB model related to the $30 \mathrm{~km} / \mathrm{h}$ speed limit. Bayesian analyses are used to do the linear regression and build the decision tree.

The results confirmed the relevance of the model which is able to explain $53 \%$ of the behavioural intention variance. Linear regression confirmed previous results from the literature: attitude and behavioural control are the two most significant determinants of intention prediction according to TPB. In addition, perceived importance and frequency are two significant dimensions in this study. The decision tree is doubly relevant. On the one hand, it determines the most significant questions for predicting intent in nearly $60 \%$ of cases, and it is much better than a random prediction $(\mathrm{p}=.01)$. On the other hand, it identifies drivers who report an intention that matches their answers to other questions and drivers who report a dissonant intention in relation to their answers to significant questions in the model.

The study provides support to politicians, researchers and communicators who are charging the implementation of this type of measures. Awareness campaigns can have an impact on representational aspects in order to develop a sense of perceived importance. Urban planning in conjunction with public policies to reduce speed limit can also help to increase the frequency of behaviour related to compliance with the $30 \mathrm{~km} / \mathrm{h}$ and to perceive this speed as legitimate.
\end{abstract}

Keywords: Theory of planned behavior, past behaviors, decision trees, public policy, speed limit.

\section{Theoretical framework}

\subsection{Decision trees}

Decision trees can help to predict certain behaviours (Quinlan, 1993). They are easy to interpret and understand to predict situations and/or determine outcome preferences in different contexts. In this study, the decision tree compares drivers' self-reported intentions and their intentions predicted by their answers to a questionnaire. Ordinary trees consist of a root, branches, nodes and leaves. In statistics, decision trees are composed of circles (nodes) and segments (branches). The first node is the root. Two or several branches may grow from it. The last node of the chain is a leaf and no branches grow from it. Each node represents a variable, and branches give a set of values, which can be predicted from observations of individuals, social groups, or specific characteristics. Decision trees have already been used in medicine (Li, Gluer, Eastell, Felsenberg, Reid, Rox and Lu, 2012; Podgorelec, Kokol, Stiglic and Rozman, 2002), and notably to identify significant predictors of child abuse in Canada (Fallon, Ma, Allan, Pillhofer, Trocmé and Jud, 2013). 


\subsection{Theory of planned behaviour}

This research is based on the Theory of Planned Behaviour (TPB) (Ajzen, 2011; Ajzen and Albarracin, 2007). According to this model, intention to enact a behaviour can be predicted by taking into account three factors: attitude, subjective norms and perceived behavioural control (PBC). Attitude refers to the individual's positive or negative evaluation of a specific behaviour. Subjective norms are based on whether individuals think that people of importance to them (e.g. parents, friends) approve or disapprove of the behaviour. Finally, PBC refers to individuals' perceptions of their capacity to achieve the behaviour. These three factors are also impacted by beliefs (Emin, 2003) and past behaviors (Ajzen, 1991). The latter are the best predictor of future behaviour (Conner and Armitage, 1998; Ouellette and Wood, 1998). In this study, we especially focus on the influence of social-cognitive factors on the intention to comply with the specific speed limit of $30 \mathrm{~km} / \mathrm{h}$. Research has shown the relevance of the TPB for mobility, risk-taking and traffic issues by studying the consumption of alcohol (McGhie, Lewis and Hyde, 2012; Moan and Rise, 2011), the use of mobile phones (Przepiorka, Błachnio and Sullman, 2018; Waddell and Wiener, 2014), the behaviour of pedestrians (Xu, Li and Zhang, 2013) and motorcyclists (Özkan, Dogruyol, Lajunen, Yıldırım and Çoymak, 2012). The TPB has also been applied to the compliance with speed limits, as well for motorists as motorcyclists (Chorlton, Conner and Jamson, 2012; Elliott, 2010; Eyssartier, 2012; Leandro, 2012; Wallén Warner and Åberg, 2008).

\subsection{Self-report habit index}

According to the contribution of past behaviours in the prediction of future behaviours, studies have tried to combine the TPB model with the Self-Report Habit Index (SRHI) (Cestact, 2009). The SRHI (Verplanken and Orbell, 2003) measures several dimensions of habit: automatic activation, perceived ease, behavioural frequency, relevance to self-identity and history of enactment. It has been used in various fields, and notably in the field of transportation and travel mode choices (Aarts, Verplanken and von Knippenberg, 1997; Verplanken, Myrbakk and Rudi, 2005). But it has never been used to understand drivers' habits with regard to speed or compliance with speed limits. However, drivers often object to speed limit reduction measures because compliance with speed limits usually depends on two major factors. Environmental conditions (curved or straight sections, visibility, reliability of road signs and posted speed limits) are one of the most impact factor influencing drivers' speed (Fitzpatrick, Carlson, Brewer and Wooldridge, 2001). This point refers to drivers' habits to comply with speed limit according to environmental circumstances. Secondly, drivers generally drive faster than the limit that they themselves regard as being safe (Goldenbeld and van Schagen, 2007). This point refers to drivers' beliefs in circumstances in which they can comply or not speed limits.

\subsection{Aims of the current study}

The purpose of the current study is to understand drivers' intentions by comparing drivers' self-reported intentions and the theoretical intentions expected from the drivers' answers given to different variables. From a theoretical perspective, this research aims to provide information on socio-cognitive determinants of drivers' decisions. From an applied perspective, the study aims to facilitate the implementation of speed limit reduction measures.

\section{Method}

\subsection{Participants}

Participants ( $\mathrm{n}=129$, Mean Age=22.4 y.o., $\mathrm{SD}=3.8$, range: 18-30) are drivers and students at the University of Angers. There are $78 \%$ females and $22 \%$ males. They anonymously answer an online questionnaire in French. They were informed that their participation was voluntary and unpaid.

\subsection{Instrument}

The questionnaire comprised fifteen items, based on the TPB and the SRHI. There were five items related to the TPB (attitude, subjective norms, PBC). Three of them were related to subjective norms according to different social referents (parents, friends, motorists). Five further items were related to beliefs and identification. According to the SRHI, four items were related to habits such as frequency, automatic activation history of enactment and ease. Questions were presented randomly. Answers were given on a 6-point scale from 1 (completely disagree) to 6 (totally agree). 


\subsection{Analysis}

Cronbach's alpha $(\alpha=.92)$ indicates very good reliability (Nunnaly, 1978). Analyses were conducted using R software and Bayesian analysis. Regarding our methodology with R software, we used the BayesFactor package and the regressionBF function. The calculation method is based on the JZS (Rouder, Speckman, Sun, Morey and Iverson, 2009). Here, the dependent variable is the intention and the 14 other questions are used as independent variables. The determinants explained $53 \%$ of the variance for intention to comply with the $30 \mathrm{~km} / \mathrm{h}$ speed limit $[\mathrm{F}(14,376)=30.25, \mathrm{p}<.0001, \mathrm{r} 2=.53]$. This is a very high value with regards to the average explanation of the TPB around 39\% (Armitage and Conner, 2001).

\section{Results}

\subsection{Construction of the decision tree}

The construction of the decision tree is based on the CART algorithm (Breitman, Friedman, Olshen and Stone 1984). Each node divides the tree into two branches that lead to variables. The first node (top of the tree) reveals the most significant variable splitting the sample into two groups. Each branch concerns the part of the sample answering upper than the modal value or answering lower than the modal value. At the end of the tree (bottom), the last leaf indicates the theoretical intention to comply with the $30 \mathrm{~km} / \mathrm{h}$ speed limit. This intention is represented by a number between 1 and 6 ; the higher the number, the greater the theoretical intention. This theoretical intention is resulting from drivers' answers to the different questions selected for the model.

Figure 1. Decision tree contributing to predict the intention of driving at 30km/h.

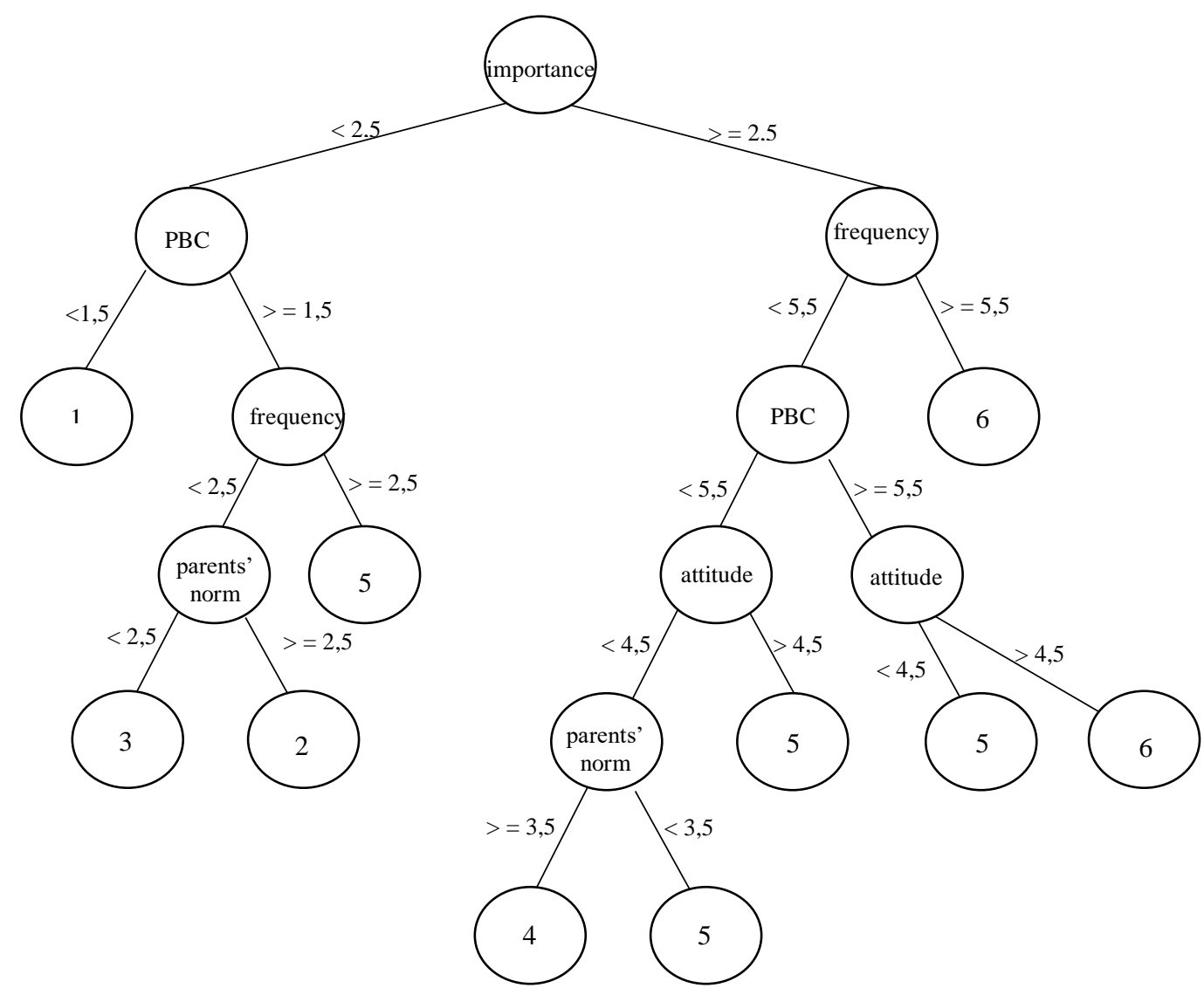

The model that we can use to predict participants' intentions to comply with the $30 \mathrm{~km} / \mathrm{h}$ speed limit is illustrated on Figure 1 and it refers to the variable perceived importance, frequency, PBC, attitude and eventually perceived parental norm. The number at the end of the tree corresponds to the theoretically expected intention of the participant. We can then compare this theoretical answer (prediction) with the participant's self-reported intention (intention) (Table 1). Numbers in bold correspond to the number of participants for whom the predicted and self-reported intention values were the same. 
The decision tree in our model has a significant predictive value of drivers' intention to comply with the $30 \mathrm{~km} / \mathrm{h}$ speed limit. It gives an exact prediction for $58.1 \%$ of the participants (i.e. 75 participants) when random predictions would obtain an exact prediction for $16.67 \%$. The difference between exact predictions and random predictions is significant $\left(\chi^{2}\right.$ Yates Correction $\left.(\mathrm{YC})=14.47, \mathrm{df}=5, \mathrm{p}<.013\right)$. The same can be calculated for acceptable predictions (equal to or within one point of difference with the participant's answer). This calculation gives an acceptable prediction for $84.5 \%$ of the participants (i.e. 109 participants) when the random predictions would be acceptable for $44.4 \%$. The difference between acceptable predictions and random predictions is significant $(\chi 2 \mathrm{YC}=22.84, \mathrm{df}=5, \mathrm{p}<.001)$.

Table 1. Data of the first group for constructing the decision tree.

\begin{tabular}{|c|c|c|c|c|c|c|c|}
\hline \multicolumn{8}{|c|}{ Prediction } \\
\hline \multirow{7}{*}{ Intention } & & 1 & 2 & 3 & 4 & 5 & 6 \\
\hline & 1 & 5 & 0 & 1 & 0 & 0 & 0 \\
\hline & 2 & 1 & 7 & 3 & 2 & 3 & 0 \\
\hline & 3 & 0 & 3 & 6 & 3 & 8 & 0 \\
\hline & 4 & 0 & 2 & 0 & 19 & 12 & 2 \\
\hline & 5 & 1 & 0 & 0 & 4 & 23 & 3 \\
\hline & 6 & 0 & 0 & 0 & 1 & 5 & 15 \\
\hline
\end{tabular}

\section{Discussion}

The results confirmed the relevance of combining the TPB and SRHI variables for predicting drivers' intention to comply with the $30 \mathrm{~km} / \mathrm{h}$ speed limit. The study confirms that habits such as the frequency of doing the behaviour influences intentions. Results also confirm the role of beliefs, such as the perceived importance of the speed limit, confirming the relationship between legitimacy and compliance with speed limits (Goldenbeld and van Schagen 2007).

Using a decision tree to predict intention is more effective than traditional predictions like linear regression because it makes possible the comparison between self-reported intentions and theoretical intentions expected from participants' answers about the other variables. When the two values differ, it would be interesting to examine in more depth the reasons for the discrepancy and rationalization process (Bordarie, 2015, 2017).

This study has some limitations starting with the sample which has the concern of not-being representative of the general population as it was composed of a majority of female students. Moreover, there is an issue with regards to the self-reported data that can imply social desirability related to the compliance with laws. However, guaranteeing anonymity and confidentiality should have minimized this effect. Finally, we should remind that intentions and behaviours are different.

\section{References}

Aarts, H., Verplanken, B., \& Knippenberg, A. van (1997). Habit and information use in travel mode choices. Acta Psychologica, 96, 1-14. https://doi.org/10.1016/S0001-6918(97)00008-5

Ajzen, I. (1991). The theory of planned behavior. Organizational Behavior and Human Decision Processes, 50, 179-211. https://doi.org/10.1016/0749-5978(91)90020-T

Ajzen, I. (2011). The theory of planned behaviour: Reactions and reflections. Psychology and Health, 26, 1113-1127. https://doi.org/10.1080/08870446.2011.613995

Ajzen, I., and Albarracin, D. (2007). Predicting and changing behavior: A reasoned action approach. In I. Ajzen, D. Albarracin, and R. Hornik (Eds.), Prediction and Change of Health Behavior: Applying the reasoned action approach (pp. 3-21). Mahwah, NJ: Lawrence Erlbaum Associates Publishers.

Armitage, C. J., and Conner, M. (2001). Efficacy of the theory of planned behaviour: A meta-analytic review. British journal of social psychology, 40(4), 471-499. https://doi.org/10.1348/014466601164939

Bordarie, J. (2015). Représentations sociales et mobilité urbaine durable. Thèse de Doctorat, Université d'Angers.

Bordarie, J. (2017). Rationalization processes between social representations and semantic blocks theory. In D. Compagno (Dir.), Quantitative Semiotic Analysis. Springer.

Breitman, L., Friedman, J.H., Olshen, R.A., and Stone, C.J. (1984). Classification and Regression Trees. Wadsworth, Belmont, California.

Cestac, J. (2009). Habitude et principe de compatibilité dans le modèle du comportement planifié: décisions pro-environnementales et automobile. Thèse de Doctorat, Université de Nanterre-Paris X. 
Chorlton, K., Conner, M., and Jamson, S. (2012). Identifying the psychological determinants of risky riding: An application of an extended Theory of Planned Behaviour. Accident Analysis and Prevention, 49, 142-153. https://doi.org/10.1016/j.aap.2011.07.003

Conner, M., and Armitage, C. J. (1998). Extending the theory of planned behavior: A review and avenues for further research. Journal of Applied Social Psychology, 28, 1429-1464. https://doi.org/10.1111/j.1559-1816.1998.tb01685

Elliott, M.A. (2010). Predicting motorcyclists' intention to speed: Effects of selected cognitions from the theory of planned behaviour, self-identity and social identity. Accident Analysis and Prevention, 42, 718-725. https://doi.org/10.1016/j.aap.2009.10.021

Emin, S. (2003). L'intention de créer une entreprise des chercheurs publics: le cas français. Thèse de doctorat, Université Pierre Mendès France, Grenoble, France.

Eyssartier, C. (2012). Dépassement de la limitation de vitesse sur route limitée à $90 \mathrm{~km} / \mathrm{h}$ : étude sur les motards peu expérimentés du département de la Sarthe. In S. Gaymard and A. Egido (Eds.), Sécurité et facteurs humains dans les transports: une approche multidisciplinaire (pp. 253-266). Paris: L'Harmattan.

Fallon, B., Ma, J., Allan, K., Pillhofer, M., Trocmé, N., and Jud, A. (2013). Opportunities for prevention and intervention with young children: lessons from the Canadian incidence study of reported child abuse and neglect. Child and adolescent psychiatry and mental health, 7(1), 4. https://doi.org/10.1186/1753-2000-7-4

Fitzpatrick, K., Carlson, P., Brewer, M., and Wooldridge, M. (2001). Design factors that affect driver speed on suburban streets. Transportation Research Record: Journal of Transportation Research Board, 1751, 18-25. https://doi.org/10.3141/1751-03

Goldenbeld, C., and Schagen, I. van (2007). The credibility of speed limits on $80 \mathrm{~km} / \mathrm{h}$ rural roads: the effects of road and person(ality) characteristics. Accident Analyses and Prevention, 39 (6), 1121-1130. https://doi.org/10.1016/j.aap.2007.02.012

Leandro, M. (2012). Young drivers and speed selection: A model guided by the Theory of Planned Behavior. Transportation Research Part F: Traffic Psychology and Behaviour, 15(3), 219-232. https://doi.org/10.1016/j.trf.2011.12.011

Li, C., Gluer, C.C., Eastell, R., Felsenberg, D., Reid, D.M., Rox, D.M., and Lu, Y. (2012). Tree-structured subgroup analysis of receiver operating characteristic curves for diagnostic tests. Academic Radiology, 19(12), 1529-1536. https://doi.org/10.1016/j.acra.2012.09.007

McGhie, A., Lewis, I., and Hyde, M.K. (2012). The influence of conformity and group identity on drink walking intentions: comparing intentions to drink walk across risky pedestrian crossing scenarios. Accident Analysis and Prevention, 45(2), 639-645. https://doi.org/10.1016/j.aap.2011.09.035

Moan, I., and Rise, J. (2011). Predicting intentions not to "drink and drive" using an extended version of the theory of planned behavior. Accident Analysis and Prevention, 43(4), 1378-1384. https://doi.org/10.1016/j.aap.2011.02.012

Nunnaly, J. (1978). Psychometric theory. New York: McGraw-Hill.

Ouellette, J. A., and Wood, W. (1998). Habit and intention in everyday life: The multiple processes by which past behavior predicts future behavior. Psychological Bulletin, 124, 54-74. https://doi.org/10.1037/0033-2909.124.1.54

Podgorelec, V., Kokol, P., Stiglic, B., and Rozman, I. (2002). Decision trees: an overview and their use in medicine. Journal of medical systems, 26(5), 445-463. https://doi.org/10.1023/A:1016409317640

Przepiorka, A. M., Błachnio, A. P., and Sullman, M. J. (2018). Factors influencing intentions to text while driving among Polish drivers. Transportation Research Part F: Traffic Psychology and Behaviour, 55, 306-313. https://doi.org/10.1016/j.trf.2018.03.015

Quinlan, J.R. (1993). C4.5: Programs for Machine Learning, Morgan Kaufmann, San Francisco.

Rouder, J.N., Speckman, P.L., Sun, D., Morey, R.D., and Iverson, G. (2009). Bayesian t-tests for accepting and rejecting the null hypothesis. Psychonomic Bulletin and Review, 16, 225-237. https://doi.org/10.3758/PBR.16.2.225

Verplanken, B., and Orbell, S. (2003). Reflections on Past Behavior: A Self-Report Index of Habit Strength1. Journal of Applied Social Psychology, 33(6), 1313-1330. https://doi.org/10.1111/j.15591816.2003.tb01951.x

Waddell, L. P., and Wiener, K. K. K. (2014). What's driving illegal mobile phone use? Psychosocial influences on drivers' intentions to use handheld mobile phones. Transportation Research Part F: Traffic Psychology and Behaviour, 22, 1-11. https://doi.org/10.1016/j.trf.2013.10.008

Wallén Warner, H., and Ảberg, L. (2008). Drivers' beliefs about exceeding the speed limits. Transportation Research Part F: Traffic Psychology and Behaviour, 11, 376-389. https://doi.org/10.1016/j.trf.2008.03.002

Xu, Y.S., Li, Y.J., and Zhang, F. (2013). Pedestrians' intention to jaywalk: Automatic or planned? A study based on a dual-process model in China. Accident Analysis and Prevention, 50, 811-819. https://doi.org/10.1016/j.aap.2012.07.007 